\title{
Políticas públicas de transferência de renda e a questão da segurança alimentar dos beneficiários: efetividades e entraves do Programa Bolsa Família
}

\author{
Daiane Roncato Cardozo Traldi ${ }^{1}$ \\ Luiz Manoel de Moraes Camargo Almeida²
}

\section{Resumo}

Este trabalho trata de questões que cercam o Programa Bolsa Família em relação às influências de seus recursos financeiros sobre a situação alimentar de seus beneficiários. O objetivo foi diagnosticar as principais efetividades e entraves do Bolsa Família no município de Araraquara/SP, com recorte analítico em elementos de segurança alimentar, a partir de informações das famílias beneficiárias e gestores/técnicos responsáveis pelo programa local. Os resultados apontam que, embora o maior gasto das famílias seja com a alimentação, há a prevalência de insegurança alimentar em 95\% das famílias, o que mostra que o programa é importante para melhorar, de imediato, as situações adversas de vida das famílias, mas não garante, por si só, a segurança alimentar destas. No entanto, os dados são bem significativos na constatação de que programas como o Bolsa Família são essenciais na complementaridade de outras políticas estruturais para o desenvolvimento e inclusão social dessas famílias.

Palavras-chave: Avaliação de políticas públicas. Programa Bolsa Família. Efetividades. Entraves. Segurança alimentar e nutricional.

1 Mestre em Desenvolvimento Regional e Meio Ambiente. Pesquisadora do Núcleo de Pesquisa em Desenvolvimento Local (NPDL) e Núcleo de Pesquisa e Documentação Rural (NUPEDOR) do Centro Universitário de Araraquara/SP (UNIARA).

2 Prof. Dr. Adjunto da Faculdade de Agronomia e Engenharia de Alimentos da Universidade Federal de Goiás e Pesquisador do Mestrado em Desenvolvimento Regional e Meio Ambiente do Centro Universitário de Araraquara/SP (UNIARA). 
Políticas públicas de transferência de renda e a questão da segurança alimentar dos beneficiários: efetividades e entraves do Programa Bolsa Família

Daiane Roncato Cardozo Traldi • Luiz Manoel de Moraes Camargo Almeida

\section{Introdução}

A pobreza e a fome são grandes e antigos desafios, mas são recentemente tratadas como um problema social a ser enfrentado pela sociedade, governos e ações. São temas de debates e discussões de diversos pesquisadores e gestores públicos, que buscam encontrar possíveis alternativas para a construção de uma sociedade mais justa e igualitária.

Nesse contexto, se insere a abordagem das políticas públicas voltadas para a assistência social, especialmente as que visam o combate às desigualdades sociais, à fome e à pobreza; a promoção da Segurança Alimentar e Nutricional (SAN) e a inclusão de pessoas de risco e vulnerabilidade social. A fim de tentar minimizar e/ou erradicar estes problemas, o Governo Federal (GF) brasileiro optou por investir em políticas públicas compensatórias ou os chamados programas de Transferência Condicionada de Renda (TCR).

Esses programas enquadram-se no conceito de proteção social como investimento em capital humano, tendo como pressuposto o fato de que a reprodução da pobreza se deve à falta de investimento nas capacidades dos indivíduos e buscam, mediante ou através do condicionamento da transferência, gerar incentivos para estes investimentos (VILLATORO, 2010). Os programas de transferência de renda possuem três principais estratégias: prevenção, enfrentamento e suavização da pobreza, as quais são orientadas para atenuar o impacto do risco (que as pessoas ou comunidades pobres estão expostas) e, uma vez que a situação de pobreza já é existente, são adotadas para minimizar os riscos futuros (DUARTE; SAMPAIO; SAMPAIO, 2009).

Um dos maiores problemas encontrados na dimensão dessas políticas públicas diz respeito à eficiência, à eficácia e a sua continuidade, o que deixa aberto o caminho dessas iniciativas, isto é, se elas poderão representar casos concretos de políticas públicas, se são apenas programas que duram determinado período, se são apenas instrumentos sem políticas bem direcionadas ou ainda políticas com instrumentos ineficazes (ALMEIDA, 2008). Assim, há 
a necessidade de se avaliar e aprimorar o diálogo e a articulação desses programas e das instituições públicas envolvidas para se discutir a perspectiva de inclusão social e a capacidade de ação dos agentes envolvidos nessas políticas públicas.

Este trabalho trata especificamente do Bolsa Família, um programa de transferência condicionada de renda, destinado às famílias em situação de pobreza (com renda mensal por pessoa de $\mathrm{R} \$ 70,00$ a $\mathrm{R} \$ 140,00$ ) e extrema pobreza (com renda mensal por pessoa de até R\$ 70,00), que atualmente se configura como a política social mais importante do país e a de maior transferência de renda do mundo, atendendo mais de 12 milhões de famílias em todos os municípios brasileiros.

Por ser um programa bastante repercutido, alvo de críticas e apologias, apresenta inúmeras indagações nos diversos segmentos em que atua (renda, saúde, educação, trabalho infantil, oferta de trabalho, dentre outros). No caso deste artigo, discutem-se questões em relação à segurança alimentar dos beneficiários do programa, principalmente ligadas à renda, tais como: se o programa vai além do acesso à renda e propicia elementos de segurança alimentar nas famílias assistidas; se o perfil de segurança alimentar dos beneficiários e a sua renda per capita familiar condizem com a necessidade de eles receberem o auxílio do programa; ou seja, há que se pensar em que medida o acesso aos recursos financeiros por intermédio de programas de transferência de renda, no caso o Bolsa Família, amplia as possibilidades da segurança alimentar das famílias mais vulneráveis (SEGALL-CORRÊA; SALLES-COSTA, 2008).

Nesse sentido, este estudo buscou identificar as principais efetividades e entraves do Programa Bolsa Família no município de Araraquara/SP, tendo como recorte analítico elementos de segurança alimentar tratada de maneira ampla. E, a partir disso, fornecer subsídios importantes para uma reflexão mais aprofundada sobre o funcionamento do programa local e nacional.

A seguir, apresenta-se uma breve revisão teórico-metodológica sobre a concepção mais ampla de segurança alimentar na abordagem da avaliação de políticas públicas de transferência de 
Políticas públicas de transferência de renda e a questão da segurança alimentar dos beneficiários: efetividades e entraves do Programa Bolsa Família

Daiane Roncato Cardozo Traldi • Luiz Manoel de Moraes Camargo Almeida

renda. Em seguida, os contrapontos em relação ao Programa Bolsa Família. Posteriormente, são detalhados os procedimentos e instrumentos utilizados na construção da pesquisa. Por fim, são analisados e discutidos os resultados, seguidos das considerações finais.

\section{Contornos teórico-metodológicos sobre a temática: elementos de segurança alimentar na abordagem da avaliação de políticas públicas de transferência de renda}

\subsection{O processo de avaliação de políticas públicas: um desafio ainda não resolvido?}

Dentro do estudo sistemático das políticas públicas (LASSWELL, 1956 apud SOUZA, 2006) há um modelo teórico de estágios ou ciclos chamados de policy cicle ou ciclo de políticas públicas, que buscava explicações sobre o processo de produção de políticas. Após algumas considerações de autores distintos, os estágios resumiram-se às seguintes fases: agenda-setting (quando um problema chama a atenção de uma política); formulação (quando o governo formula as opções para um problema); decisão (escolha das opções; é determinado um curso de ação ou não ação); implementação (quando o governo coloca ação em prática); avaliação (os resultados da política são monitorados pelo governo e por atores sociais), sendo esse último o foco do presente trabalho.

A avaliação deve abranger o processo de formulação e implementação das ações e os resultados, tornando-se instrumento fundamental para o aperfeiçoamento ou reformulação das ações desenvolvidas (AGUILLAR; ANDER-EGG, 1994 apud BELLONI; MAGALHÃES; SOUZA, 2001). Almeida (2008) diz que a avaliação de políticas públicas não é simplesmente um instrumento de aperfeiçoamento ou redirecionamento dos programas empreendidos pelo governo, mas, especialmente, uma ferramenta capaz de prestar contas à sociedade das ações governamentais. 


\section{Para Silva:}

É um processo de análise que permite emitir juízo de valor sobre os resultados e o mérito de uma determinada ação, verificar se os objetivos propostos foram alcançados e se foram importantes para alterar as condições iniciais de uma determinada situação. (SILVA, 2001).

Para tanto se utilizam métodos e técnicas adequados. A autora apresenta alguns conceitos sobre os critérios de análise usualmente propostos para a avaliação de políticas públicas: a eficiência é aquela que mede a relação entre os instrumentos (tempo, recursos financeiros e técnicos) empregados na implementação de uma determinada política e os resultados alcançados; a eficácia avalia a relação entre os objetivos e os resultados efetivos, ou seja, em que medida os objetivos foram alcançados; e, a efetividade verifica se os resultados e/ou impactos das ações causaram mudanças efetivas nas condições sociais anteriores a sua implementação. Também coloca os tipos de avaliação (diagnóstica, processual e global) e suas diferentes abordagens: quantitativa, qualitativa, mista, aplicação de formulários e questionários, levantamento de dados em fontes documentais, realização de entrevista e grupos focais.

Vale ressaltar aqui um procedimento metodológico, expressado por valores qualificáveis, no qual Silva (2008) ${ }^{3}$ aborda como sendo um instrumento valioso para fazer suas análises: o Grupo Focal, que alia exame profundo de uma dada realidade e o ponto de vista dos sujeitos envolvidos, buscando identificar sentimentos, percepções, atitudes e ideias dos participantes a respeito de um determinado assunto.

Nesse sentido, é necessário aprimorar o monitoramento e avaliação dos programas que vêm sendo implementados, como

3 Apresenta os resultados de uma pesquisa realizada por um grupo de pesquisadoras das Universidades Federais do Maranhão (UFMA) e do Piauí (UFPI), que formaram uma rede de pesquisa com o objetivo de desenvolver um estudo sobre o Programa Bolsa Família nos dois Estados, em relação à sua implementação e a avaliação do processo de Unificação dos Programas de Transferência de Renda no Brasil. 
Políticas públicas de transferência de renda e a questão da segurança alimentar dos beneficiários: efetividades e entraves do Programa Bolsa Família

Daiane Roncato Cardozo Traldi • Luiz Manoel de Moraes Camargo Almeida

colocam Santos e Santos (2007, p. 1029): "a avaliação de políticas e programas tornou-se um compromisso tanto quanto um desafio", pois, no Brasil, a experiência sobre avaliação de programas de combate à fome e à pobreza é ainda pouco significativa, sistemática e não muito extensa. Além de que, o enfoque na avaliação de políticas públicas (tido como um processo para a melhoria das ações e estratégias do governo) apresenta uma diversidade analítica e metodológica, devido às contribuições das diversas áreas do conhecimento, tanto por pesquisadores acadêmicos como por gestores.

\subsection{O conceito de segurança alimentar e nutricional: uma resposta à vulnerabilidade social?}

As políticas públicas de transferência de renda integram políticas de proteção social e combate à pobreza em diferentes países do mundo. São destinadas às famílias que passam por um contexto de vulnerabilidades também do ponto de vista da segurança alimentar e nutricional (acesso à terra, água, bens e serviços públicos, condições dignas de moradia e consumo de alimentos). De acordo com o Ibase (2008), apresentam vantagens (fortalecimento da economia local; autonomia das famílias beneficiárias; impacto na demanda por serviços de saúde e educação, por meio das contrapartidas de alguns programas) e desvantagens (problemas na focalização; forma de utilização dos recursos etc.).

No Brasil, o governo federal vem claramente investindo na transferência de renda condicionada, complementando ou substituindo outros programas de intervenção, por meio da unificação de programas ligados aos setores de assistência social, educação e saúde. O Programa Bolsa Família ${ }^{4}$, hoje tido como uma das políticas mais importantes do governo federal brasileiro, compromete-se com o enfrentamento das questões alimentares, já que objetiva, além do combate à pobreza, o combate à fome e a promoção da Segurança Alimentar e Nutricional (SAN).

4 Será discutido na próxima seção. 
Historicamente, o conceito de SAN vem sendo fortalecido, ampliado e refletido na intersetorialidade das políticas públicas federais, sendo capaz de transformar a realidade econômica e social (CUSTÓDIO et al., 2011). O tema SAN é bastante amplo, envolvendo aspectos tanto de oferta (produção, desenvolvimento sustentável, abastecimento e comercialização), quanto de demanda (aproveitamento e aquisição) de alimentos.

O conceito de segurança alimentar, antes fundado com base nos Direitos Humanos, ao final da Segunda Grande Guerra Mundial, com a crise dos agricultores em grande parte dos países industrializados, voltou-se à questão do acesso (demanda e distribuição). Para Belik (2003), esse conceito levou a um melhor conhecimento da situação alimentar sob três aspectos: quantidade, qualidade e regularidade no acesso aos alimentos. Segundo o autor, cabe ressaltar o conceito desses aspectos. $\mathrm{O}$ acesso aos alimentos diferencia-se da disponibilidade dos alimentos, ou seja, os alimentos podem estar disponíveis, mas não acessíveis à camada mais pobre da população. A qualidade refere-se a consumir os alimentos com dignidade (sem riscos de contaminação ou apodrecimento); e a regularidade diz respeito ao acesso constante à alimentação (pelo menos três vezes ao dia).

Na década atual, o Brasil tem vivenciado a incrustação de políticas públicas de segurança alimentar nos diversos âmbitos governamentais. $\mathrm{O}$ conceito mais amplo de segurança alimentar começou a se constituir como pauta de políticas públicas, destinadas à redução da fome e ao aumento de ações solidárias no país, nos primeiros anos do século XX. Desde 1997, quando a Cúpula Mundial da Alimentação (uma arena de representação dos governos dos países vinculados à Organização das Nações Unidas - ONU) finalmente conseguiu produzir, em consenso, um conceito ${ }^{5}$ de segurança alimentar

5 A SAN diz respeito à realização do direito de todos ao acesso regular e permanente de alimentos de qualidade, em quantidade suficiente, sem comprometer o acesso a outras necessidades essenciais, tendo como base práticas alimentares promotoras de saúde, que respeitem a diversidade cultural e que sejam social, econômica e ambientalmente sustentáveis. 
Políticas públicas de transferência de renda e a questão da segurança alimentar dos beneficiários: efetividades e entraves do Programa Bolsa Família

Daiane Roncato Cardozo Traldi • Luiz Manoel de Moraes Camargo Almeida

amplo para subsidiar políticas públicas aplicáveis nos países desenvolvidos e subdesenvolvidos, alguns programas começaram a ser executados no Brasil. De lá para cá, os esforços de vários governos no país (locais, estaduais e federais) produziram a efetivação de várias políticas de segurança alimentar (PAULILLO; PESSANHA, 2002).

As políticas de segurança alimentar devem responder por três dimensões: produção (nas áreas rurais e urbanas), distribuição (suplementar ou emergencial a grupos específicos), acesso (ações e comercialização) e consumo (educação alimentar e consumo sustentável) de alimentos. Devem também estar ligadas a elementos e/ou valores fundamentais da população: a) saúde; b) higiene; c) meio ambiente; d) autenticidade; e) solidariedade. "Todos esses valores são socialmente construídos e compartidos em redes de políticas focadas para a funcionalidade e adaptação de um padrão alimentar com equidade para a população mal nutrida" (ALMEIDA et al., 2006, p. 209).

Os valores ligados ao eixo da saúde (PAULILLO; PESANHA, 2002) referem-se às dimensões dietética e farmacêutica ligadas à composição nutricional dos alimentos. Para tanto, a educação alimentar da população mais vulnerável é fundamental. O eixo da higiene e seguridade dos alimentos engloba a ausência de tóxicos ou elementos nocivos, sendo necessárias informações, garantias e o controle sobre as condições da produção, distribuição e embalagens (certificação dos produtos). $\mathrm{O}$ meio ambiente está relacionado ao ecológico ou orgânico, produção sem tóxicos e respeito ao mesmo. $\mathrm{O}$ eixo da autenticidade está ligado aos valores naturais e tradicionais da produção agroalimentar, aos conhecimentos muitas vezes herdados de práticas alimentares, à valorização da origem dos produtos e às especificações dos processos produtivos. Por fim, o eixo da solidariedade envolve valores morais e ideológicos que impulsionam a participação da população bem nutrida em ações humanísticas no processo de consumo.

Os elementos trabalhados neste estudo remetem-se à Escala Brasileira de Medida de Insegurança Alimentar - EBIA e suas associações com os eixos da saúde, relacionada a problemas crônicos 
de saúde dos beneficiários e da solidariedade, relacionada às suas vulnerabilidades, nas quais contam os fatores renda, consumo alimentar, escolaridade, trabalho e proteção social.

A EBIA é um método desenvolvido nos EUA, adaptado para a realidade brasileira pela Universidade Estadual de Campinas - UNICAMP (juntamente com outras instituições), que mensura a situação alimentar domiciliar, buscando captar distintas dimensões da Insegurança Alimentar (IA). É aplicado diretamente a uma pessoa da família, que seja responsável pela alimentação do domicílio, por meio de um formulário com 15 questões fechadas de respostas do tipo sim ou não, referentes aos últimos três meses. As questões envolvem assuntos relacionados às condições financeiras para aquisição de alimentos da família, bem como a quantidade e regularidade das refeições de adultos e menores de 18 anos (SEGALL-CORRÊA; SALLES-COSTA, 2008). Esta escala permite a classificação das famílias em quatro categorias:

- Segurança Alimentar (SA): quando não há restrição alimentar de qualquer natureza, nem mesmo a preocupação com a falta de alimentos no futuro;

- Insegurança Alimentar Leve (IAL): quando há preocupação ou incerteza quanto ao acesso aos alimentos, portanto, risco para a sustentabilidade e, ainda, comprometimento da qualidade da dieta;

- Insegurança Alimentar Moderada (IAM): quando aparecem restrições quantitativas especialmente relevantes entre pessoas adultas, e;

- Insegurança Alimentar Grave (IAG): quando há redução importante da quantidade de alimentos disponíveis, tanto para a alimentação de adultos quanto para a de crianças que residem no domicílio. Nesta última, há evidente quebra nos padrões usuais de alimentação das famílias, com alta possibilidade de ocorrência de fome.

O artigo de Segall-Corrêa e Marin-Leon (2009) descreve os resultados do uso da EBIA a partir de seu processo de validação 
Políticas públicas de transferência de renda e a questão da segurança alimentar dos beneficiários: efetividades e entraves do Programa Bolsa Família

Daiane Roncato Cardozo Traldi • Luiz Manoel de Moraes Camargo Almeida

até os inquéritos de abrangência nacional, sua utilização pelos gestores municipais e para a produção acadêmica; justifica ainda a relevância desta escala como instrumento auxiliar das políticas públicas de combate à fome e à pobreza no Brasil.

\subsection{Concepções e reflexões sobre o Programa Bolsa Família: uma sucessão de contrapontos}

Criado em 2003 pelo Ministério do Desenvolvimento Social e Combate à Fome (MDS), no Governo Luiz Inácio Lula da Silva, o Bolsa Família é a unificação, racionalização e ampliação dos quatro programas sociais já existentes (Bolsa Escola, vinculado ao Ministério da Educação; Bolsa Alimentação e Cartão-Alimentação, vinculados ao Ministério da Saúde; Auxílio-Gás, vinculado ao Ministério de Minas e Energia) do Governo Fernando Henrique Cardoso (FHC).

Faz parte de um dos quatro eixos articuladores do Programa Fome Zero (PFZ), tendo como principais objetivos: a diminuição imediata da pobreza, por meio da transferência direta de renda às famílias; o reforço do acesso das famílias aos direitos sociais básicos nas áreas de educação, saúde e assistência social, por meio das condicionalidades, o que contribui para as famílias romperem o ciclo da pobreza entre gerações; e a integração com outras ações e programas dos governos e da sociedade para apoiar as famílias a superarem a situação de vulnerabilidade e pobreza (BRASIL, 2010).

Além do critério da renda, para continuar recebendo os benefícios, as famílias devem assumir e cumprir com os compromissos das condicionalidades, que implicam: na área da educação, manter os filhos nas escolas, com frequência escolar mensal mínima de $85 \%$ para crianças e adolescentes entre 6 e 15 anos e mínima de $75 \%$ para adolescentes entre 15 e 17 anos; na saúde, o acompanhamento do calendário vacinal e do crescimento e desenvolvimento de crianças menores de 7 anos, das mulheres na faixa etária de 14 a 44 anos, se gestantes ou nutrizes (lactantes), acompanhar 
o pré-natal, sua saúde e do bebê; na área de assistência social, crianças e adolescentes com até 15 anos em risco ou retiradas do trabalho infantil pelo Programa de Erradicação do Trabalho Infantil (PETI), devem participar dos Serviços de Convivência e Fortalecimento de Vínculos (SCFV) do PETI e obter frequência mínima de $85 \%$ da carga horária mensal.

O Bolsa Família é hoje a mais importante das políticas sociais do Governo Federal. No início de sua implementação era visto como estratégia política de governo e hoje tem sua importância consolidada, sendo alvo de críticas e diversas indagações acadêmicas, devido às repercussões de seus resultados nos segmentos em que atua: renda, saúde, educação, oferta de trabalho, alimentação, trabalho infantil, dentre outros (TRALDI, 2011).

Por um lado, apresenta resultados positivos, como a redução do índice de miséria no Brasil entre 2002 e 2006 (FGV, 2008); um modelo de políticas sociais altamente elogiado internacionalmente (WEISSHEIMER, 2006); a contribuição para o crescimento da escolaridade no país; impactos na economia brasileira, o que resultou num crescimento adicional do Produto Interno Bruto (PIB) entre 2005 e 2006 (DANTAS, 2009), dentre outros. Por outro, os críticos do Bolsa Família procuram focar mais irregularidades na execução do programa, como: o recebimento dos benefícios por pessoas não habilitadas, duplicidades na folha de pagamento e a ocorrência de fraudes; percebem o programa como sendo de caráter assistencialista; afirmam que a frequência escolar como condicionalidade não garante um bom aprendizado etc.

O trabalho de Castro et al. (2009) procura demonstrar empiricamente as percepções da sociedade brasileira sobre os objetivos do Bolsa Família, com base em amostra de 6.001 beneficiários. Os autores chegam a duas principais conclusões: que o PBF adquiriu legitimidade política junto à sociedade brasileira, ou seja, "a população reconhece o Programa e entende que ele está sendo utilizado de forma adequada, mesmo considerando problemas na sua execução" (CASTRO et al., p. 350); e indica que a opinião da sociedade deve ser considerada como importante elemento de 
Políticas públicas de transferência de renda e a questão da segurança alimentar dos beneficiários: efetividades e entraves do Programa Bolsa Família

Daiane Roncato Cardozo Traldi • Luiz Manoel de Moraes Camargo Almeida

avaliação de políticas públicas, ou seja, "não se trata apenas de verificar o nível de apoio ou rejeição a uma determinada política, mas de entender que uma análise adequada do que pensa a população poderá contribuir para verificar sua real efetividade" (CASTRO et al., p. 350).

O artigo de Estrella e Ribeiro (2008) discute os indicadores de acompanhamento da gestão das condicionalidades do Bolsa Família, o IGD (indicador global de eficiência para monitoramento da qualidade da implementação do CadÚnico e o cumprimento das condicionalidades do Bolsa Família), e analisa sua adequação para descrever a situação educacional e de saúde dos beneficiários do programa, a fim de apreender o impacto de possíveis melhorias na educação e saúde. Foi realizada uma análise sobre a eficiência do programa, indicadores socioeconômicos e informações sobre as transferências monetárias; observou-se que o IGD, na verdade, apresenta problemas de registro, principalmente no caso da saúde, onde as informações repassadas pelos municípios são precárias e mais complexas do que em relação à educação, pois o sistema de saúde é mais fragmentado e mais inseguro do que o da educação (LINDERT, 2007 apud ESTRELLA; RIBEIRO, 2008).

É uma discussão que parece não ter fim, permeada por controvérsias e contrapontos. Contudo, cabe aprofundar o debate sobre esse tema, avaliando quais os resultados da implementação do programa na vida das famílias beneficiadas, principalmente em relação à segurança alimentar e nutricional das mesmas, como objetiva este trabalho.

\section{Aspectos metodológicos: a construção da pesquisa}

O universo empírico, ou seja, o município de Araraquara está localizado na região Administrativa Central do Estado de São Paulo (RA12), considerado o mais rico e de maior poder aquisitivo, com um elevado Índice de Desenvolvimento Humano Municipal (IDH-M) e uma população estimada de 200.666 habitantes (ARARAQUARA, 2010). 
A Secretaria Municipal de Assistência e Desenvolvimento Social (SMADS) é o órgão responsável pelo PBF no município, juntamente com os Centros de Referência de Assistência Social (CRAS), situados em bairros de maior vulnerabilidade social. Estes órgãos se relacionam também com as Secretarias Municipais de Saúde, Educação (para o acompanhamento das condicionalidades do programa) e da Agricultura, com o Conselho Municipal de Segurança Alimentar e Nutricional (COMSAN), instância designada ao controle social do programa local, e com o Centro de Referência Especializado de Assistência Social (CREAS), responsável pela proteção social especial às famílias (crianças, jovens, mulheres, idosos) vítimas de violências.

A pesquisa de natureza aplicada utilizou métodos descritivos, de objetivo exploratório, com abordagens qualitativas e quantitativas. O objetivo exploratório da pesquisa partiu do levantamento bibliográfico de dados secundários da temática e do objeto de estudo a fim de ampliar, o mais detalhadamente possível, seu conhecimento. As abordagens qualitativas e quantitativas basearam-se na coleta de dados primários com as observações de campo e aplicação de formulários semiestruturados.

A coleta (realizada entre os meses de fevereiro e março com beneficiários - e agosto e setembro de 2010 - com gestores), tabulação e análise dos dados foram feitas pelo próprio pesquisador, sendo o banco de dados construído com instrumentos da ferramenta Microsoft Excel 2007.

A amostragem ${ }^{6}$ foi elaborada de acordo com o número de famílias beneficiárias atendidas pela Secretaria Municipal de Assistência e Desenvolvimento Social e pelos Centros de Referência de Assistência Social. Segundo o gestor local do programa (informação verbal), em Araraquara (jul. 2010), são aproximadamente 4.000 famílias beneficiárias.

As técnicas quantitativas foram baseadas na metodologia da Rede Interdisciplinar de Estudo e Pesquisa em Segurança Alimentar

6 Apresentada no Apêndice Metodológico ao final do trabalho. 
Políticas públicas de transferência de renda e a questão da segurança alimentar dos beneficiários: efetividades e entraves do Programa Bolsa Família

Daiane Roncato Cardozo Traldi • Luiz Manoel de Moraes Camargo Almeida

e Nutricional - Rede Alimenta ${ }^{7}$ da Universidade Estadual de Campinas, no caso, os 100 formulários aplicados às famílias beneficiárias. Já as técnicas qualitativas fundamentaram-se pela aplicação de entrevistas abertas com gestores e técnicos do programa (representantes das Secretarias Municipais de Assistência Social e de Educação, e do Conselho Municipal de Segurança Alimentar e Nutricional), baseadas no roteiro utilizado pela pesquisa do Instituto Brasileiro de Análises Sociais e Econômicas (IBASE, 2008). Foi realizada uma entrevista com um representante de cada entidade. Essas questões tiveram como objetivo levantar aspectos relacionados ao funcionamento do programa (gestão, cadastramento, condicionalidades controle social, intersetorialidade, gestão compartilhada) e às opiniões dos gestores sobre as repercussões do programa na segurança alimentar das famílias.

Além da apresentação formal $^{8}$ da pesquisa e de uma questão relacionada a outros programas dos quais beneficiários participavam, contida na primeira folha, os formulários (para os beneficiários) apresentam 8 módulos referentes às informações gerais do domicílio; à caracterização da segurança alimentar/fome dos maiores e menores de 18 anos de idade; às características sociodemográficas dos titulares/chefes e membros das famílias; à caracterização do padrão de consumo alimentar do beneficiário; às condições de saúde e de trabalho; ao apoio e proteção social; à caracterização do trabalho e da renda da família; e em relação à inserção do programa na família. Esses indicadores (sociodemográficos e socioeconômicos) foram cruzados com os níveis de in-

7 O formulário da Rede Alimenta, o qual engloba o método da EBIA - Módulo II do Formulário Pesquisa do Perfil sociodemográfico e socioeconômico das famílias beneficiárias do Bolsa Família em Araraquara/SP (TRALDI, 2011) - possibilita o cruzamento com variáveis sociodemográficas, padrão de consumo alimentar, local de moradia, redes de proteção social, trabalho e renda, entre outras, que abrem brechas analíticas ao desenvolvimento do trabalho e ao programa em questão (ALMEIDA, 2008).

8 A aplicação dos formulários aos beneficiários, bem como as entrevistas aos gestores e técnicos do programa foram agendadas mediante o encaminhamento de ofícios e aceitação e realizadas na própria Secretaria e nos Centros de Referência de Assistência Social, de forma aleatória no caso dos beneficiários (conforme iam ao local buscar atendimento, eram abordados pelo pesquisador). 
segurança alimentar das famílias, resultando em algumas relações analisadas a seguir.

A pesquisa seguiu o protocolo de ética em pesquisa com seres humanos e foi aprovada pelo Comitê de Ética do Centro Universitário de Araraquara.

\section{Resultados e discussões}

\subsection{Contextualização da gestão local do programa: análise qualitativa}

A gestão do Bolsa Família, submetida pelo MDS a critérios iguais para todos os municípios, funciona nacional e localmente sob uma rede de coordenação descentralizada entre órgãos responsáveis pela assistência social, educação, saúde e controle social.

No município de Araraquara, em relação aos profissionais que atuam na gestão, o gestor local afirma que há o empenho quanto ao conhecimento (atualização) do programa e motivação, apesar das dificuldades com a remuneração e número de funcionários em relação à grande demanda pelo programa. Quanto ao conhecimento desses profissionais, contradiz com as questões aplicadas aos representantes da Educação e da Assistência Social, que não souberam responder qual a instância de controle social do município, dados da saúde e sobre o programa em si. Essas desinformações são agravantes para o funcionamento do programa local.

As atividades principais do programa estão: no cadastramento e recadastramento das famílias (cumprimento das metas), no contato com outros municípios sobre as pendências das famílias, nas visitas domiciliares, no acompanhamento das condicionalidades de saúde e educação, na coordenação e controle das atividades da Secretaria, dos CRAS e das demais Secretarias de Governo, na realização da gestão de benefícios, no Sistema de Cadastro Único, e na interlocução com o MDS, além da divulgação das ações e das regras do programa. 
Políticas públicas de transferência de renda e a questão da segurança alimentar dos beneficiários: efetividades e entraves do Programa Bolsa Família

Daiane Roncato Cardozo Traldi • Luiz Manoel de Moraes Camargo Almeida

No cumprimento dessas atividades encontram-se alguns entraves, como: a omissão de renda e da correta composição das unidades familiares, a insistência de famílias fora dos critérios do programa, que frequentemente tentam se encaixar para o recebimento dos benefícios e o não fornecimento por parte do MDS de ferramentas de consulta sobre a situação socioeconômica das famílias, ou seja, as informações atuais das famílias chegam somente através das entrevistas e de visitas domiciliares. Contudo, apesar dessas dificuldades, a avaliação da gestão de Araraquara pelo MDS atingiu o valor de 0,84 (pelo Índice de Gestão Descentralizada IGD) em julho de 2010, o que indica um bom índice de desempenho da gestão local.

Os CRAS possuem papel fundamental no atendimento socioassistencial das famílias beneficiárias tanto do Bolsa Família quanto de outros programas, pois são eles que fornecem as orientações para as famílias em relação à questão de documentação, de sua condição social, como elas podem melhorar de vida, são encaminhadas para cursos de qualificação, são atendidas por psicólogos, ou seja, são várias ações de maneira a ajudar essas famílias com maiores dificuldades a resolverem essas questões. No entanto, os gestores dos CRAS afirmam que a localização, a falta de investimento na estrutura física dos CRAS e a falta de funcionários são grandes entraves, pois a demanda é grande e se torna difícil o acompanhamento da evolução das famílias atendidas.

Nesse sentido, investimentos em infraestrutura, funcionários, ferramentas de consulta e maior capacitação por parte do MDS proporcionarão uma evolução da capacidade de ação da gestão, e, consequentemente, isso fará com que os beneficiários tenham um maior contato, uma maior orientação e acompanhamento e cumpram mais as condicionalidades do programa, conseguindo assim, de forma mais rápida, deixar o programa para a conquista de sua emancipação.

De acordo com a representante da Educação (2010), em relação às condicionalidades da educação, o município de Araraquara está muito bem estruturado com recorde de frequência de $91 \%$. Os 
entraves encontrados estão nas dificuldades de os beneficiários cumprirem seus compromissos, especialmente quando abandonam as escolas (ou por desinteresse ou negligência dos pais). Em relação ao contato com as demais entidades gestoras, só há a articulação com o gestor local. A representante da Educação mostrou que a Secretaria não articula com a Secretaria da Saúde e nem com a Instância de Controle Social (ICS) do município, pois não soube identificar o órgão responsável pelo controle social e fiscalização, concentrando suas respostas apenas na área da educação. Ou seja, não há a intersetorialidade entre as entidades responsáveis pelas condicionalidades, fator que é crucial para a eficiência do programa local.

Em relação ao controle social do programa, o representante do Conselho Municipal de Segurança Alimentar e Nutricional (COMSAN) informou que as competências desse órgão seriam de apurar as irregularidades, de fiscalizar, em conjunto com a Secretaria Municipal de Assistência e Desenvolvimento Social, com o Gestor local, mas não soube responder como acontece esse acompanhamento, essa fiscalização, ou seja, não há avaliação regular das denúncias e irregularidades, apenas um contato com o Gestor.

O processo de transparência do Bolsa Família está relacionado com o acompanhamento das contrapartidas por parte do controle social local. Em tese, evidencia-se a importância de que estes canais participativos, ou seja, os conselhos municipais, atuem efetivamente como instrumentos de accountability, exercendo influência positiva na aplicação dos recursos públicos e no desempenho governamental na gestão dessas políticas públicas. No entanto, esta pesquisa mostra o que "acontece" na realidade. Como apresentado acima, não há atuação efetiva do COMSAN no município de Araraquara, sendo que vários fatores colaboram para isso: não participação de beneficiários nos conselhos, pouca representatividade dos poucos participantes, principalmente os responsáveis pela prestação de contas em relação às condicionalidades do programa: saúde, educação e assistência social.

Outro ponto, quanto à segurança alimentar local, é que, de acordo com o representante do Conselho, o município é bem 
Políticas públicas de transferência de renda e a questão da segurança alimentar dos beneficiários: efetividades e entraves do Programa Bolsa Família

Daiane Roncato Cardozo Traldi • Luiz Manoel de Moraes Camargo Almeida

diferenciado e avançado. No entanto, alguns dados apresentados (a seguir) neste trabalham contestam isso, como o fato de $95 \%$ dos beneficiários do Bolsa Família apresentarem insegurança alimentar, sendo $26 \%$ do nível mais grave, ou seja, há a fome entre crianças e adultos em 26 famílias numa amostra de 100 famílias.

Isso gera a necessidade de rever alguns pontos, tanto nos programas de segurança alimentar desenvolvidos no município quanto no próprio Bolsa Família. É necessária uma maior divulgação sobre os programas de segurança alimentar desenvolvidos no município para os beneficiários do Bolsa Família, mesmo porque, a quase totalidade dos beneficiários $(98 \%)$ respondeu não conhecer ou participar de algum programa de segurança alimentar, e, às vezes, eles até participam, mas não sabem ou não conhecem pelos nomes. E a articulação desses programas é fundamental para a rede de proteção social em torno dos beneficiários, como por exemplo, por meio do restaurante popular, onde o beneficiário pagará menor tarifa na alimentação.

\subsection{Perfil dos beneficiários: características sociodemográficas e socioeconômicas}

A maior porcentagem dos titulares do programa é de mulheres (94\%) e mães solteiras (separadas) com crianças (49\%), porém, Araraquara apresentou uma alta porcentagem de titulares mulheres com companheiros e crianças $(42 \%)$. Em relação à titularidade do programa, há um "consenso" por parte de gestores e beneficiados de que a titularidade do PBF deve ser prioritariamente das mulheres; a pesquisa do Ibase (2008) aponta como algumas justificativas mais recorrentes, o fato de as mulheres conhecerem melhor as necessidades das famílias e a sua tendência em gastar os benefícios mais com a alimentação e com os filhos. Esse "consenso" está em acordo com o decreto-lei que criou o Bolsa Família, que impõe tal titularidade; no entanto, questões de independência, poder de decisão, poder de compra, pressão entre os sexos são aspectos que necessitam ser ainda aprofundados nesse tipo de programa. 
Em relação à escolaridade, a maioria dos titulares sabe ler e escrever, mas apresentam ainda baixos graus de escolaridade: $67 \%$ têm o ensino fundamental e $8 \%$ têm o ensino médio incompleto, sendo apenas $20 \%$ com ensino médio completo e uma baixíssima porcentagem com ensino superior (3\%). Em 39\% das famílias a maior escolaridade é o fundamental; e em $76 \%$ há pelo menos de 1 a 3 menores de 18 anos estudantes.

A metade das famílias (51\%) respondeu que existia pelo menos uma pessoa com algum problema crônico de saúde, como diabetes e/ou hipertensão, ou seja, grande parte ainda necessita de cuidados em relação à saúde. Já em relação ao acesso a bens públicos básicos, como rede de esgoto, energia, coleta de lixo e distribuição de água, são aspectos favoráveis às famílias, o que não acontece normalmente em muitos casos, mas, com isso, o município de Araraquara mostra estar avançando em relação às condições de saneamento.

Em relação à situação de trabalho dos titulares das famílias, somente $14 \%$ são trabalhadores formais, ou seja, têm registro em carteira; $30 \%$ trabalham sem registro em carteira (temporariamente ou por conta própria) e $30 \%$ estão desempregados, procurando emprego. $O$ percentual de titulares autônomos e desempregados é elevado, o que descaracteriza, para alguns, o programa quanto à proposta de evitar as práticas assistencialistas. De acordo com outras pesquisas (IBASE, 2008), o fato de os titulares serem, na maioria, mulheres, pode explicar o baixo índice de trabalhadores permanentes, pois as mulheres dedicam-se mais à gestão da casa.

A renda média total das famílias advindas de todas as formas de remuneração (bolsa família, trabalho, pensão ou aposentadoria) mostra que mais da metade das famílias (64\%) possuem renda menor do que um salário mínimo (R\$ 510,00) e apenas 36\% recebem igual ou mais do que um salário mínimo.

Das famílias que possuem crianças frequentando escolas ou creches, 51\% recebem em média uma vez ao dia refeição escolar, $35 \%$ recebem, em média, duas ou mais vezes ao dia, sendo apenas $1 \%$ que não recebe e em $13 \%$ das famílias não se aplicava a questão, 
Políticas públicas de transferência de renda e a questão da segurança alimentar dos beneficiários: efetividades e entraves do Programa Bolsa Família

Daiane Roncato Cardozo Traldi • Luiz Manoel de Moraes Camargo Almeida

pelo fato de que não tinham crianças menores de 14 anos; ou seja, a merenda escolar é complementar para $87 \%$ das famílias com menores de 14 anos, o que pode contribuir, mesmo que indiretamente, para a melhora dos níveis de segurança alimentar; além de ser importante para o orçamento doméstico (menos gastos em casa com alimentação das crianças), de acordo com o Instituto Brasileiro de Análises Sociais e Econômicas (2008).

A maioria das famílias $(60 \%)$ recebe ajuda em forma de alimento de entidades sociais, amigos, parentes, programas municipais e estaduais, dentre outros; $40 \%$ não recebem nenhum tipo de ajuda. Desses $60 \%, 78 \%$ recebem de forma esporádica e $22 \%$ regularmente; a maioria (47\%) recebe cesta básica e $12 \%$ recebem leite (em pó e saquinho). As doações da ajuda em forma de alimento são, na maioria (45\%), advindas da Assistência Social do município (cesta básica e leite), sendo o restante proveniente das igrejas, das próprias famílias dos beneficiários e de amigos. De acordo com o Instituto Brasileiro de Análises Sociais e Econômicas (2008), a solidariedade entre a população gera rede de apoio em situações de escassez alimentar. Em questão de ajuda financeira, as famílias recebem em maior porcentagem (67\%) recursos somente advindos do Bolsa Família e 20\% recebem, além do Bolsa Família, o programa Estadual Renda Cidadã.

Os principais gastos das famílias com os benefícios do Bolsa Família são na maioria com a alimentação (69\%), com material escolar (14\%) e com vestuário (5\%) das crianças e adolescentes (roupas, uniformes e acessórios), resultado que é visto também em outras pesquisas na mesma ordem, o que mostra que o benefício é significativamente direcionado à satisfação alimentar.

\subsection{Insegurança alimentar e Bolsa Família : o que os dados revelam}

Em relação à situação alimentar, 95\% das famílias beneficiadas pelo Programa Bolsa Família no município de Araraquara/SP 
apresentaram algum grau de insegurança alimentar - IA (Gráfico 1). Deste percentual, $26 \%$ encontram-se com IA grave, ou seja, há a fome extrema entre adultos e/ou crianças.

Mesmo o fato de o município de Araraquara estar localizado na região mais rica e de maior poder aquisitivo do Estado de São Paulo, apresentando elevados indicadores de desenvolvimento econômico, como Produto Interno Bruto (PIB) e social, como Índice de Desenvolvimento Humano (IDH), os resultados apontam níveis de insegurança alimentar semelhantes a municípios de regiões menos desenvolvidas em relação a estes indicadores no Brasil, como o caso do nordeste (IBASE, 2008).

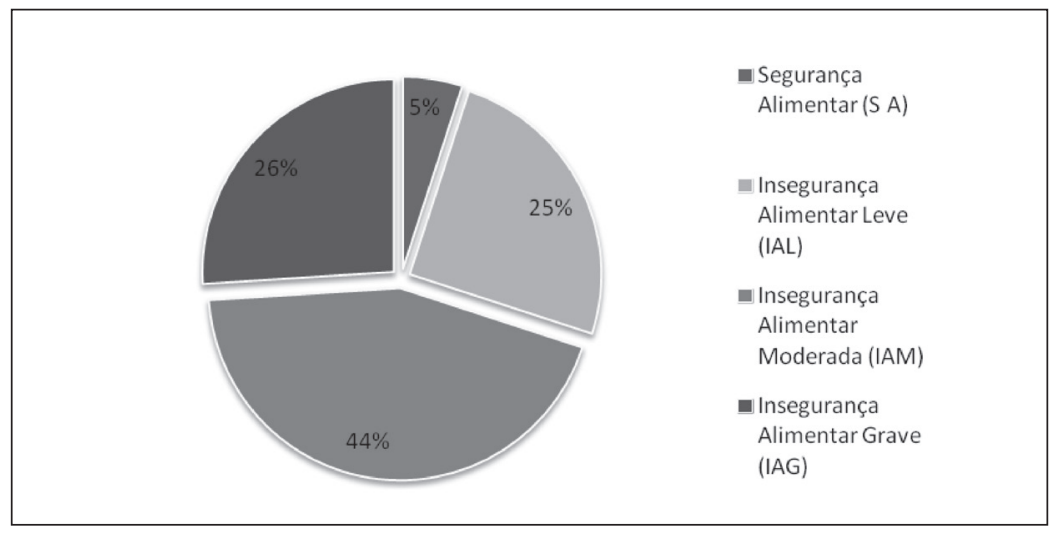

Gráfico 1 - Distribuição das famílias beneficiárias de acordo com a Escala Brasileira de Insegurança Alimentar - EBIA

Fonte: Pesquisa de campo, 2010

O nível de IA mais grave é predominante nas famílias em que os titulares não sabem ler e escrever; os chefes são pensionistas, trabalhadores temporários ou sem emprego; que afirmam ter algum problema crônico de saúde, como diabetes ou hipertensão e as famílias que recebem ajuda em forma de alimento (do Bolsa Família e de parentes e amigos). A menor prevalência de IAG ocorre nas famílias que gastam mais os benefícios do programa com a alimentação. 
Políticas públicas de transferência de renda e a questão da segurança alimentar dos beneficiários: efetividades e entraves do Programa Bolsa Família

Daiane Roncato Cardozo Traldi • Luiz Manoel de Moraes Camargo Almeida

Em relação à renda (Gráfico 2), nas famílias com renda média do Bolsa Família maior que R\$ 83,50 (média total) prevalecem os níveis de IAG e IAM e nas que possuem renda menor do que a média total prevalecem o nível de IAL e a SA, o que leva à constatação que o benefício está direcionado às famílias que mais necessitam (que apresentam os mais altos níveis de IA).

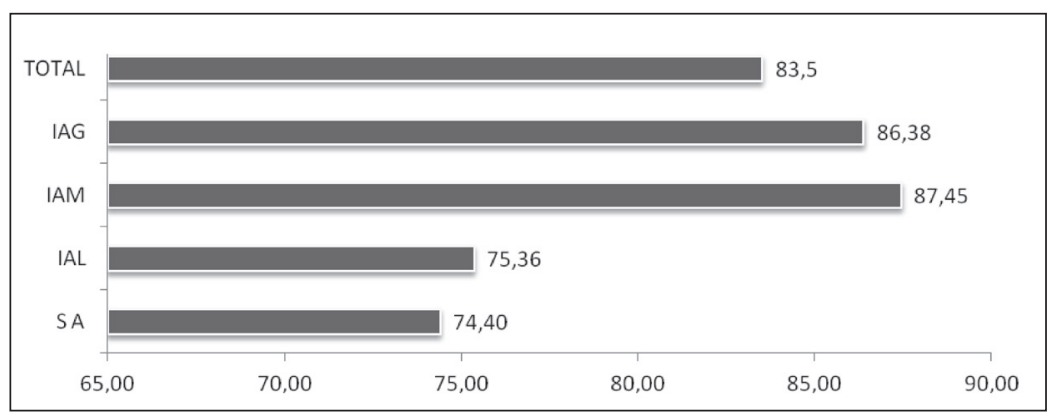

Gráfico 2 - Relação entre a renda média do Bolsa Família das famílias beneficiárias e o nível de insegurança alimentar

Fonte: Pesquisa de Campo, 2010

As famílias gastam em média um total de $\mathrm{R} \$ 233,95 \mathrm{com}$ alimentação. As famílias que gastam mais do que a média apresentam níveis de SA e IAL e as famílias que gastam menos do que a média total apresentam níveis de IAG e IAM (Gráfico 3).

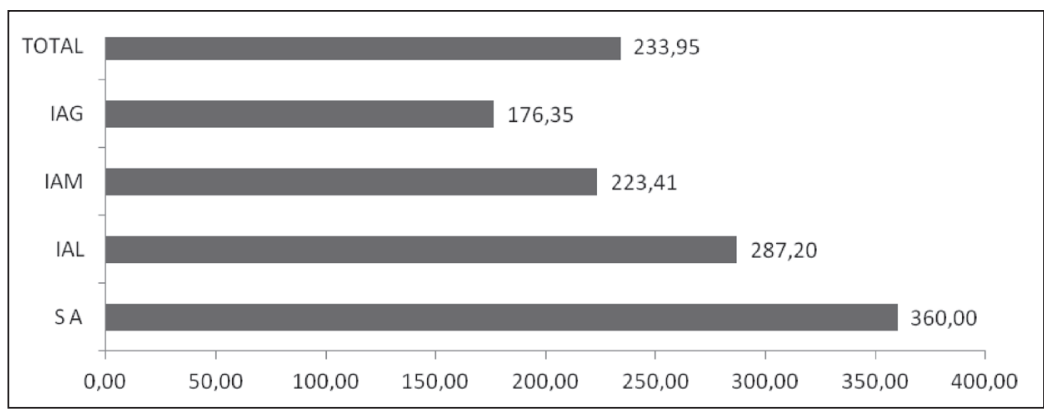

Gráfico 3 - Relação entre o gasto médio com alimentação das famílias beneficiárias e o nível de insegurança alimentar

Fonte: Pesquisa de campo, 2010 
O Gráfico 4 mostra que a SA é predominante nas famílias que têm uma renda média total de $R \$ 822,40$, ou seja, quase o dobro do que a média total (R\$ 421,84$)$. Os níveis de IAM e IAG prevalecem nas famílias com renda média abaixo da média total.

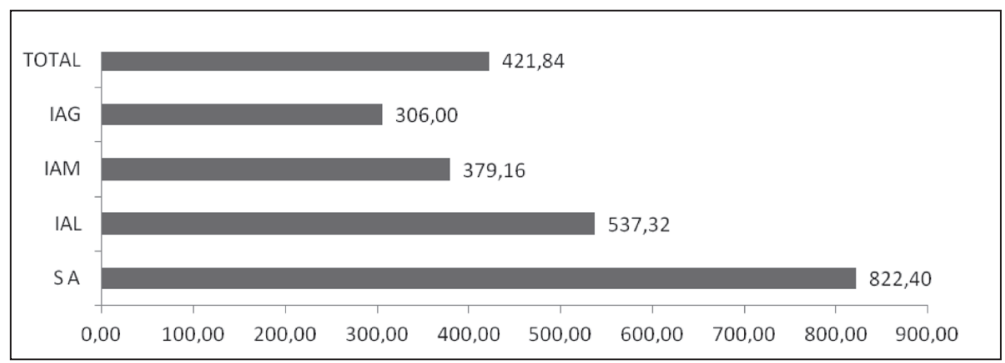

Gráfico 4 - Relação entre a renda média total das famílias beneficiárias e o nível de insegurança alimentar

Fonte: Pesquisa de campo, 2010

A porcentagem da renda média do Bolsa Família sobre renda média total das famílias (Gráfico 5) é de 43\% (quase a metade). As famílias em que os benefícios do programa representam maior porcentagem apresentam os níveis de IA mais graves (IAG e IAM).

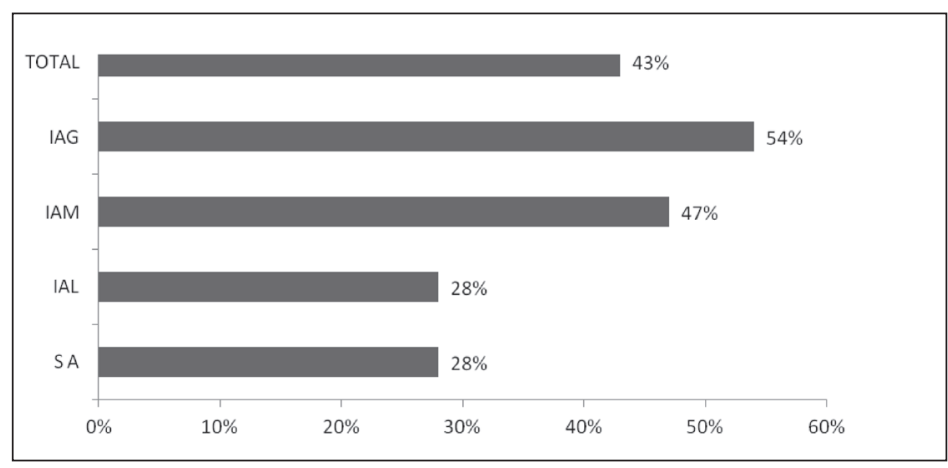

Gráfico 5 - Relação entre a porcentagem da renda média do Bolsa Família sobre a renda média total das famílias beneficiárias e o nível de insegurança alimentar

Fonte: Pesquisa de campo, 2010 
Políticas públicas de transferência de renda e a questão da segurança alimentar dos beneficiários: efetividades e entraves do Programa Bolsa Família

Daiane Roncato Cardozo Traldi • Luiz Manoel de Moraes Camargo Almeida

A maioria das famílias gasta mais do que recebe com a alimentação (Gráfico 6). A porcentagem do gasto médio com alimentação sobre a renda média total ${ }^{9}$ das famílias é de $109 \%$. Novamente constata-se que as famílias que gastam mais com alimentação são as que apresentam maiores níveis de IA. Todas as famílias que apresentam algum grau de insegurança alimentar gastam mais com alimentação do que suas rendas familiares, levando, portanto, a indícios de formação de redes de cooperação e proteção social no município.

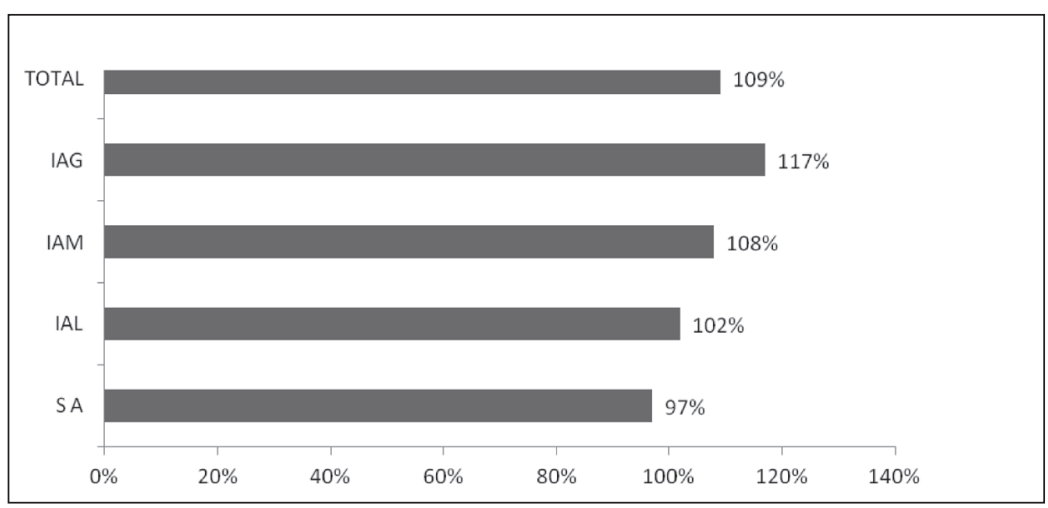

Gráfico 6 - Relação entre a porcentagem do gasto médio com alimentação sobre a renda média total das famílias beneficiárias e o nível de insegurança alimentar

Fonte: Pesquisa de campo, 2010

A porcentagem da renda média do Bolsa Família sobre o gasto médio com alimentação é de $49 \%$. As famílias em que os benefícios têm maior representatividade nos gastos com alimentação são as que apresentam os níveis mais altos de IA. Famílias com insegurança alimentar moderada ou grave têm a renda proveniente do programa responsável por mais da metade gasta com alimentação, sinalizando o efeito significativo sobre a segurança alimentar dos beneficiários.

9 A renda média total das famílias inclui: salário, pensão, aposentadoria, Renda cidadã e o Bolsa Família. 


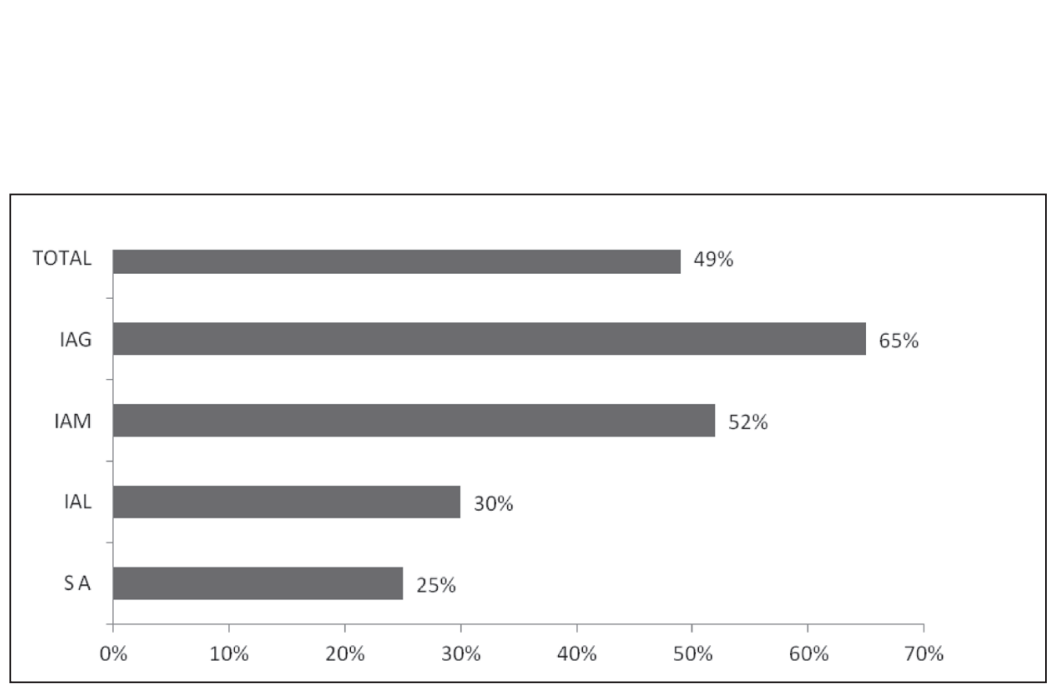

Gráfico 7 - Relação entre a porcentagem da renda média do Bolsa Família sobre o gasto médio com alimentação das famílias beneficiárias e o nível de insegurança alimentar

Fonte: Pesquisa de campo, 2010

\subsection{Inserção do programa na família: embriões de inclusão social}

Em relação ao tempo de inserção no programa e aos benefícios, $55 \%$ das famílias afirmam que o benefício financeiro foi interrompido pelo menos uma vez, na maioria das vezes por falta de atualização cadastral. Grande porcentagem (65\%) das famílias diz que o benefício não é suficiente e deveria aumentar em média 98,34 reais, sendo $58 \%$ na faixa de 20 a 80 reais e $36 \%$ de 90 a 150 reais.

Quanto à renda total familiar, $40 \%$ dos titulares afirmam que chegam ao final do mês com muita dificuldade; $33 \%$ com dificuldade e $22 \%$ com alguma dificuldade. Mas, $61 \%$ das famílias avaliam o programa como sendo bom e $25 \%$ como muito bom, pois, segundo eles, é uma "ajudinha a mais" na compra de alimentos, matéria escolar, remédios, pagamento de contas etc.

Quanto ao conhecimento do programa, 75\% das famílias afirmam não conhecer a fundo sobre o programa, suas condicionalidades e benefícios; $17 \%$ afirmam conhecer mais ou menos; o 
Políticas públicas de transferência de renda e a questão da segurança alimentar dos beneficiários: efetividades e entraves do Programa Bolsa Família

Daiane Roncato Cardozo Traldi • Luiz Manoel de Moraes Camargo Almeida

que mostra que há a falta de interesse por parte dos beneficiários, pois, segundo o gestor local, há vários meios de comunicação (rádio, folders, palestras) por parte da gestão.

As entidades responsáveis pelo programa local são bem vistas pelas famílias $(76 \%)$, sendo que os CRAS, na maioria das vezes, são bem mais elogiados, pelo fato de criarem maior vínculo com as famílias por atuarem direto nos bairros de maior vulnerabilidade. Mais da metade das famílias (54\%) considera forte o esforço das entidades em manter os beneficiários dentro do programa; $97 \%$ acham que elas são fundamentais para o benefício chegar até eles.

Além dos efeitos positivos sobre a renda familiar, os beneficiários têm nas reuniões, oficinas e palestras, promovidas pelos CRAS e pela Secretaria de Assistência e Desenvolvimento Social, espaços possíveis de socialização de informações, de (re)educação associadas às atividades de capacitação, de ampliação do restrito lazer de suas vidas. Por tais condições, pode-se afirmar que as consequências do Bolsa Família se irradiam para outras dimensões da existência dos beneficiários tendo presença significativa na rede de elementos que caracterizam um processo de inclusão social.

\section{Efetividades e entraves do Programa Bolsa Família no município de Araraquara/SP}

As famílias entrevistadas encontram-se na maior parte em situações adversas: $29 \%$ das famílias pagam aluguel, sendo que mais da metade (64\%) ganha menos de um salário mínimo, 30\% não têm trabalho com registro em carteira (trabalha por conta própria), 30\% estão desempregados, procurando emprego e a maior parte gasta muito mais do que recebe com alimentação (e, ainda assim, o grau de IA é elevado); o baixo grau de escolaridade, sendo que $38 \%$ têm o ensino fundamental incompleto ( $5^{\mathrm{a}}$ a $8^{\mathrm{a}}$ série); constatou-se a existência de algum problema crônico de saúde como diabetes e hipertensão em $51 \%$ das famílias; a dependência de ajuda financeira e 
de alimentos como cestas básicas e leite (em pó e saquinho) distribuídos pela Assistência Social, igrejas, familiares, amigos, dentre outros; grande parte das famílias é chefiada por mulheres e mães separadas.

Em relação à situação alimentar, o alto índice de IA divide-se em 44\% em situação de Insegurança Alimentar Moderada (IAM), $25 \%$ em situação de Insegurança Alimentar Leve (IAL), 26\% em situação de Insegurança Alimentar Grave (IAG) e apenas 5\% encontra-se em Segurança Alimentar (SA). Destacando-se a associação dos níveis à renda, nota-se que nas famílias em que os benefícios do programa têm maior representatividade e em que os maiores gastos são com a alimentação, estão os níveis mais altos de IA, o que mostra que o programa está sendo bem direcionado.

Nos diários de campo, conforme foram aplicados os formulários aos beneficiários, anotavam-se observações em relação ao programa e a eles. Constatou-se a falta de investimento nos Centros de Referência de Assistência Social, o que prejudica os atendimentos, reuniões do programa e acompanhamento da evolução das famílias beneficiárias; a falta de conhecimento e muitas vezes de interesse pelo programa por parte dos beneficiários; problemas com as condicionalidades do programa, principalmente referentes à frequência escolar das crianças e adolescentes. Há outras situações adversas que algumas famílias enfrentam em relação a preconceitos, problemas graves de saúde e adaptação local, problemas em conseguir emprego, dentre outros.

Os Quadros 1 e 2 (dados referentes ao ano de 2010) apresentam as efetividades e entraves do programa que, diagnosticados, num primeiro momento, consideraram aspectos relevantes associados ao perfil das famílias beneficiárias, às questões sociodemográficas e socioeconômicas nas quais elas estão inseridas: ao atendimento destas pelas entidades responsáveis, as condições de moradia, renda, trabalho, escolaridade, saúde, alimentação, apoio e proteção social, níveis de insegurança alimentar, entre outros, referentes aos titulares do programa e demais membros das famílias, e ao funcionamento do programa local. 
Quadro 1 - Diagnóstico e identificação das principais efetividades e entraves do Bolsa Família em Araraquara referentes à gestão local

\begin{tabular}{|c|l|}
\hline \multicolumn{2}{|c|}{ Principais efetividades e entraves identificados } \\
\hline Efetividades & $\begin{array}{l}\text { Esforço comprometimento quanto às metas de cadastramento e } \\
\text { recadastramento, e do acompanhamento das condicionalidades, } \\
\text { propiciando um bom índice de gestão municipal; à divulgação } \\
\text { do programa e do Cadastro Único; e à articulação com as } \\
\text { demais entidades gestoras. O importante e fundamental } \\
\text { papel dos CRAS e seus funcionários localizados nos bairros } \\
\text { de maior vulnerabilidade. Interação das famílias beneficiárias } \\
\text { com as entidades provedoras. A boa reputação das entidades } \\
\text { responsáveis pelos atendimentos. }\end{array}$ \\
\hline Entraves & $\begin{array}{l}\text { Falta de investimento em infraestrutura e em funcionários } \\
\text { diante da grande demanda. Baixa remuneração dos funcionários. } \\
\text { organizacionais }\end{array}$ \\
$\begin{array}{l}\text { Espaço físico e quantidade de equipamentos inadequados para } \\
\text { os CRAS. Falta de capacitação (treinamento) de gestores. Cultura } \\
\text { conservadora do servidor público frente à necessidade de } \\
\text { constante readequação das diretrizes do programa e demandas } \\
\text { locais. Aprimoramento dos mecanismos operacionais do MDS. } \\
\text { Falta de atuação da instância de controle social, bem como a maior } \\
\text { participação dos representantes, necessitando haver a inclusão } \\
\text { de beneficiários no Conselho. Baixa intersetorialidade entre as } \\
\text { entidades responsáveis pelas condicionalidades e pelo controle } \\
\text { social. Falta maior articulação com programas complementares } \\
\text { de segurança alimentar e educação. Falta de pesquisas avaliativas } \\
\text { para aprimoramento da implementação do programa. }\end{array}$ \\
\hline
\end{tabular}

Fonte: Pesquisa de campo, 2010

Quadro 2 - Diagnóstico e identificação das principais efetividades e entraves do Bolsa Família em Araraquara referentes à situação dos beneficiários

\begin{tabular}{|c|l|}
\hline \multicolumn{2}{|c|}{ Principais efetividades e entraves identificados } \\
\hline Efetividades & $\begin{array}{l}\text { Satisfação dos beneficiários quanto ao acolhimento das } \\
\text { entidades provedoras. Boa avaliação do programa. Acesso } \\
\text { a bens públicos básicos. Sem índice de trabalho infantil. A } \\
\text { merenda escolar como complementação alimentar para as } \\
\text { crianças. Indícios de formação de rede de proteção social } \\
\text { (apoio de governo, estado, município, igrejas, parentes, } \\
\text { amigos); e a importância da constituição da gestão local nessa } \\
\text { rede. Canalização dos recursos do programa às famílias com } \\
\text { os maiores níveis de insegurança alimentar. Efeito significativo } \\
\text { dos benefícios financeiros nos gastos com alimentação. }\end{array}$ \\
\hline Entraves institucionais e \\
organizacionais & $\begin{array}{l}\text { Baixa escolaridade dos titulares do programa. Alto índice } \\
\text { de titulares desempregados. Insuficiência dos benefícios. } \\
\text { Desconhecimento pelo programa. Descumprimento das } \\
\text { condicionalidades e desatualização cadastral. Dificuldades } \\
\text { enfrentadas com a baixa renda familiar e a questão da } \\
\text { alimentação. }\end{array}$ \\
\hline
\end{tabular}

Fonte: Pesquisa de campo, 2010 


\section{Considerações finais}

De modo geral, as efetividades e entraves do Programa Bolsa Família no município de Araraquara podem ser diagnosticados, num primeiro momento, considerando aspectos relevantes referentes ao perfil das famílias beneficiárias; às questões sociodemográficas e socioeconômicas nas quais elas estão inseridas; aos níveis de Insegurança Alimentar identificados na pesquisa, através da Escala Brasileira de Medida de Insegurança Alimentar; e ao funcionamento do programa, especificamente quanto à gestão local.

Os resultados desta pesquisa alertam para a importância da integração do PBF com outros programas sociais para o melhoramento da situação de segurança alimentar (por $95 \%$ das famílias estarem com IA); das condições de saúde (por mais da metade das famílias apresentarem problemas crônicos de saúde); educação (pelo baixo grau de escolaridade); capacitação (pela grande porcentagem de titulares sem registro em carteira e desempregados); e principalmente na alimentação, visto que os maiores gastos das famílias são com alimentos, nos quais os benefícios do programa têm grande representatividade, principalmente nas famílias com os níveis mais altos de IA.

Há a necessidade também de um maior esforço em relação ao conhecimento do programa, principalmente por parte dos beneficiários, pois é um aspecto que dificulta a inserção das famílias em outros programas sociais, ou seja, faz-se necessário estabelecer e intensificar estratégias de comunicação entre os beneficiários, gestores locais e sociedade; repensar os compromissos das condicionalidades, inserindo a questão da segurança alimentar dos beneficiários; e a integração com políticas que possibilitem gerar oportunidades de emprego, de trabalho e renda, elementos necessários a real emancipação das famílias.

Desde a implementação do Programa Bolsa Família, já se passaram mais de seis anos e alguns entraves diagnosticados anteriormente ainda continuam a se expressar. A pesquisa revela alguns desafios a se conquistar, como: as diversidades de situações 
Políticas públicas de transferência de renda e a questão da segurança alimentar dos beneficiários: efetividades e entraves do Programa Bolsa Família

Daiane Roncato Cardozo Traldi • Luiz Manoel de Moraes Camargo Almeida

e desigualdades em que as famílias se encontram; o engajamento do poder local e dos próprios gestores, ou seja, maior autonomia do poder local; dificuldades encontradas em relação ao quadro de funcionários, infraestrutura e remuneração, como no caso do CRAS, este tido como uma porta de entrada para as famílias beneficiárias na rede de proteção social; integração entre os gestores da saúde, educação, assistência social e o COMSAN, não somente com o gestor local, mas entre todos, bem como a capacitação dos mesmos sobre informações específicas do programa.

Apesar dos aspectos vulneráveis, os dados são bem significativos na constatação de que programas que se afirmam como políticas públicas compensatórias têm cumprido um papel inegável no enfrentamento à exclusão social. Conclusão que não pode ser lida como uma dogmática profissão de fé a favor do programa Bolsa Família, e reforça a necessidade de seu acompanhamento por parte de pesquisas e avaliações sobre suas consequências no âmbito familiar e no espaço público. Assim, é possível delinear algumas recomendações de políticas públicas para o município de Araraquara:

a) Estabelecimento de estratégias de divulgação do programa, tanto para as famílias quanto para os gestores locais;

b) Divulgação dos programas de segurança alimentar do município para as famílias beneficiárias do Bolsa Família;

c) Implementação de programas direcionados à educação alimentar e à saúde no município;

d) Investimento no processo de formação dos gestores: cursos, palestras, treinamentos reuniões entre as esferas federal, estaduais e municipais;

e) Investimento em infraestrutura nas entidades responsáveis pelos atendimentos socioassistenciais, bem como no número de funcionários;

f) Investimento em pesquisas para aprimoramento da implementação do programa local;

g) Aperfeiçoamento dos mecanismos de avaliação do programa. 


\section{Referências}

ALMEIDA, L. M. M. C. 2008. Estrutura de governança e gestão das redes e programas de segurança alimentar: análise comparativa entre municípios paulistas. Relatório Técnico-Científico de Bolsa de Pós-Doutorado no país. Campinas: UNICAMP/ Faculdade de Engenharia Agrícola.

ALMEIDA, L. M. M. C. et al. 2006. Políticas públicas, redes de segurança alimentar e agricultura familiar: elementos para construção de indicadores de eficácia. Estudos Sociedade e Agricultura, Rio de Janeiro, v. 14, n. 2, p. 205-235.

ARARAQUARA (Prefeitura Municipal). 2010. O município. Disponível em: <http://www.araraquara.sp.gov.br/Home/Default. aspx> . Acesso em: 21 ago. 2010.

BELIK, W. Perspectivas para segurança alimentar e nutricional no Brasil. Saúde e Sociedade, São Paulo, v. 12, n. 1, p. 12-20, jan./jun. 2003.

BELLONI, I.; MAGALHÃES, H.; SOUZA, L. C. 2001. Metodologia de avaliação em políticas públicas: uma experiência em educação profissional. 2. ed. São Paulo: Cortez. (Coleção Questões da Nossa Época, v. 75).

BRASIL. Ministério do Desenvolvimento Social e Combate à Fome. 2010. Programa Bolsa Família. Disponível em: < http://www.mds. gov.br/bolsafamilia >. Acesso em: 12 ago. 2010.

CASTRO, H. C. O. et al. Percepções sobre o Programa Bolsa Família na sociedade brasileira. Opinião Pública. Campinas, SP, v. 15, n. 2, p. 333-355, nov. 2009.

CUSTÓDIO, M. B. et al. Segurança alimentar e nutricional e a construção de sua política: uma visão histórica. Segurança Alimentar e Nutricional, Campinas, v. 18, n. 1, p. 1-10, 2011. 
Políticas públicas de transferência de renda e a questão da segurança alimentar dos beneficiários: efetividades e entraves do Programa Bolsa Família

Daiane Roncato Cardozo Traldi • Luiz Manoel de Moraes Camargo Almeida

DANTAS, F. Impactos Econômicos do Bolsa Família. 2009. O Estado de São Paulo, São Paulo, p. A9, out.

DUARTE, G. B.; SAMPAIO, B.; SAMPAIO, Y. 2009. Impactos do programa Bolsa Família sobre os gastos com alimentos de famílias rurais. Economia Social Rural, Brasília, v. 47, n. 4.13 p.

ESTRELLA, J.; RIBEIRO, L. M. Qualidade da gestão das condicionalidades do Programa Bolsa Família: uma discussão sobre o índice de gestão descentralizada. Administração Pública, Rio de Janeiro, v. 42, n. 3, p. 625-641, 2008.

FUNDAÇÃO GETULIO VARGAS (FGV). 2008. Revisão do Bolsa Família é um upgrade. O Estado de São Paulo, São Paulo, p. A8, 16 mar.

INSTITUTO BRASILEIRO DE ANÁLISES SOCIAIS E ECONÔMICAS (IBASE). 2008. Repercussões do Programa Bolsa Família na Segurança Alimentar e Nutricional das famílias beneficiadas. Relatório Técnico (preliminar). Rio de Janeiro: IBASE.

LEVINE, D. M.; BERENSON, M. L; STEPHAN, D. 2000. Estatística: teoria e aplicações usando Microsoft Excel em português. Rio de Janeiro: LTC.

PAULILLO, L. F. O.; PESSANHA, L. 2002. Segurança alimentar, políticas públicas e regionalização: In. PAULILLO, L. F. et al. Reestruturação agroindustrial: políticas públicas e segurança alimentar regional. São Carlos: Edufscar.

SANTOS, S. M. C.; SANTOS, L. M. P. 2007. Avaliação de políticas públicas de segurança alimentar e combate à fome no período de 1995-2002 - Abordagem metodológica. Cadernos de Saúde Pública, Rio de Janeiro, v. 23, n. 5, p. 1029-1040.

SEGALL-CORRÊA, A. M.; SALLES-COSTA, R. Novas possibilidades de alimentação a caminho? Democracia Viva, n. 39, p. 68-73, jun. 2008.

SEGALL-CORRÊA, A. M.; MARIN-LEON, L. 2009. A segurança alimentar no Brasil: proposição e usos da escala brasileira de 
medida da insegurança alimentar (EBIA) de 2003 a 2009. Segurança Alimentar e Nutricional. Campinas, v. 16, n. 2, p. 1-19.

SILVA NETO, J. M.; MELO, R. P.; PEREIRA, S. A. 2006. Resultados notáveis na administração pública: avaliação de programas utilizando mapas estratégicos e o "Balanced Scorecard". In: 30 ENCONTRO DA ASSOCIAÇÃO NACIONAL DE PÓS-GRADUAÇÃO E PESQUISA EM ADMINISTRAÇÃO, 2006, Salvador/BA. Resumos... Salvador/BA: EnANPAD, 2006. p. 23-27.

SILVA, M. O. S. (Coord.) Avaliação de políticas e programas sociais: teoria e prática. São Paulo: Veras, 2001.

. O Bolsa Família no enfrentamento à pobreza no Maranhão

e Piauí. São Paulo: Cortez, 2008.

SOUZA, C. Políticas públicas: uma revisão da literatura. 2006. Sociologias. Porto Alegre-RS, v. 8, n. 16, p. 20-45. Disponível em: $<$ http://www.scielo.br/>. Acesso em: 6 jul. 2009.

TRALDI, D. R. C. Efetividades e entraves do Programa Bolsa Família no município de Araraquara/SP: um olhar sobre a segurança alimentar e nutricional dos beneficiários. Dissertação (Mestrado em Desenvolvimento Regional e Meio Ambiente) Centro Universitário de Araraquara (UNIARA), Araraquara, 2011.

VILLATORO, P. 2010. Programas de transferências monetárias condicionadas: experiências na América Latina. Revista CEPAL, número especial em português, p. 127-141.

WEISSHEIMER, M. A. 2006. Bolsa Família: avanços, limites e possibilidades do programa que está transformando a vida de milhões de famílias no Brasil. São Paulo: Fundação Perseu Abramo. 
Políticas públicas de transferência de renda e a questão da segurança alimentar dos beneficiários: efetividades e entraves do Programa Bolsa Família

Daiane Roncato Cardozo Traldi • Luiz Manoel de Moraes Camargo Almeida

\section{Apêndice metodológico}

Por limitações de tempo, foram aplicados 100 questionários a 100 famílias (um para cada família). Tomando a fórmula de cálculo do tamanho da amostra de (LEVINE; BERENSON; STEPHAN, 2000), calculamos o tamanho do erro amostral. A fórmula para o cálculo do tamanho da amostra é dada por:

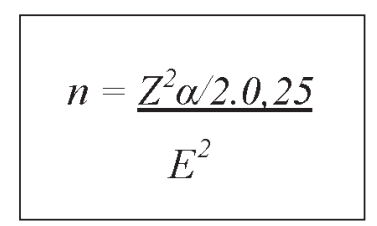

Equação 1

Onde:

$\mathrm{n}=$ Número de indivíduos na amostra.

$\mathrm{Z} \alpha / 2=$ Valor crítico que corresponde ao grau de confiança desejado (LEVINE; BERENSON; STEPHAN, 2000).

$\mathrm{E}=$ Margem de erro máximo de estimativa.

Esta fórmula é aplicada quando o $(p \text { e } q)^{10}$ não são conhecidos e quando a população é considerada infinita ${ }^{11}$. Neste caso, aplicando-se a Equação 1 (utilizando a ferramenta Microsoft Excel 2007), com os valores determinados do nível de confiança $=90 \%, \log \mathrm{Z}=$ 1,645 , o produto $\mathrm{p} \mathrm{x} \mathrm{q}=0,25$, considerando-se a amostra de $100 \mathrm{fa}$ mílias, calculou-se que o erro amostral foi de $8,22 \%$, o que é razoável para os fins da pesquisa.

10 p é igual à proporção populacional de indivíduos que pertencem à categoria que se interessa estudar e q é igual à proporção populacional de indivíduos que não pertencem à categoria que se interessa estudar $(q=1-p)$. Neste caso, $\mathrm{p}=\mathrm{q}=0,5$.

11 Quando a população de onde é retirada a amostra é muito grande, ou seja, quando a amostra tenha tamanho $n$ menor do que $5 \%$ da população (LEVINE; BERENSON; STEPHAN, 2000). 


\section{Abstract \\ Public policies for income transfer and food security of beneficiaries: barriers to effectiveness at the Bolsa Família program}

This paper seeks to contribute to the topic of evaluation of public policies for income transfer, in addressing social inequalities and promoting food security. The objective was to address the main barriers to effectiveness and "Bolsa Família" Program in the city of Araraquara/SP, focusing on analytical elements of food security treated broadly, from information from beneficiary families and managers and technicians responsible for the local program, through interviews and semi-structured forms. The results indicate that, although the majority of families is spent on food, there is the prevalence of food insecurity in $95 \%$ of households, which shows that the program is important to improve immediately, the odds of life for families, but not guarantee by itself, the food security of these. However, the data are very significant in finding that programs such as Bolsa Familia are essential complementarity of other structural policies for development and social inclusion of these families.

Keywords: Evaluation of public policies. Bolsa Família Program. Effectiveness. Obstacles. Food. Nutrition security. 
